\title{
O FUTEBOL FEMININO NO CAMPO ACADÊMICO BRASILEIRO: MAPEAMENTO DE TESES E DISSERTAÇÕES (1990-2010)
}

\author{
Leila Salvini \\ Universidade Federal do Paraná, Paraná, Curitiba, Brasil. \\ Ana Letícia Padeski Ferreira \\ Unibrasil, Paraná, Curitiba, Brasil. \\ Wanderley Marchi Júnior \\ Universidade Federal do Paraná, Paraná, Curitiba, Brasil. \\ Bolsista produtividade em pesquisa CNPQ
}

\begin{abstract}
Resumo
O objetivo deste artigo é apresentar um mapeamento de teses e dissertações sobre o futebol feminino entre os anos de 1990 e 2010. Para tanto, consultamos o banco de dados da Capes, do Nuteses e 132 Currículos Lattes de pesquisadores indicados pelo site do CNPq numa consulta por assunto e por doutores, tendo como palavras-chave: futebol feminino, gênero, esporte e mulher. Foram consideradas somente as pesquisas concluídas; dessas, três são teses e nove são dissertações. Como resultados, encontramos uma possível aproximação entre os campos esportivo e acadêmico, já que, tanto o espaço social ocupado pelo futebol feminino no campo esportivo, quanto a temática de estudo no campo acadêmico, são considerados periféricos.
\end{abstract}

Palavras-chave: Futebol feminino. Brasil. Produção científica. Teoria dos campos.

\section{Introdução}

Embora estejamos passando por um processo de mudanças e ressignificações da participação feminina nos esportes, alguns estudos apontam que o futebol feminino ${ }^{1}$ brasileiro - apesar dos avanços - ainda assume uma posição marginalizada no espaço dos esportes (FRANZINI, 2005; GOELLNER, 2005a).

Essa posição do futebol feminino no espaço dos esportes no Brasil justifica-se, dentre outros elementos, pela restrita visibilidade midiática (MOURÃO; MOREL, 2008), pelo pouco incentivo financeiro dos órgãos públicos ou de empresas privadas com fins de patrocinar as equipes, e por ser uma modalidade categorizada como amadora.

\footnotetext{
${ }^{1}$ A nossa escolha pela utilização da terminologia "futebol feminino" como palavra-chave para as buscas nos bancos de dados, se justifica por entendemos que os termos "futebol de mulheres" ou "futebol praticado por mulheres", em decorrência da recente temporalidade, não eram amplamente utilizados no período que abrange o recorte temporal da pesquisa (2000-2010). Esse fato trás a tona a reflexão de que, assim como os termos estão se adequando para um novo formato de apresentação dos gêneros, o esporte também está passando - mesmo lentamente - por um processo de ressignificações e mudanças.
}

Pensar a Prática, Goiânia, v. 17, n. 4, out./dez. 2014 
Somada a todas essas argumentações, ainda está a questão da construção do corpo feminino nos esportes (JAEGER, 2009; GOELLNER 2005b) - mais precisamente no caso do futebol e no Brasil -, que remonta aspectos históricos de um passado de proibições ${ }^{2}$ e de restrições do público feminino aos esportes que pudessem "desfeminilizá-las" (MOURÃO, 2000; GOELLNER, 2003).

Mesmo com o processo de grandes mudanças que se foram desencadeando ao longo dos anos no sentido de pluralizar a apresentação corporal da mulher atleta, e de adequação dessas mulheres à "normatividade de gênero", o preconceito diante da construção de um habitus $^{3}$ tipicamente feminino no espaço do futebol brasileiro ainda sofre interferências negativas, ou, em outras palavras, ainda é alvo de preconceitos construídos sobre pilares da dominação masculina (SALVINI, 2012).

Ainda que o preconceito de gênero seja velado, ou mascarado, ele pode ser percebido por meio da situação atual em que se encontra a modalidade no campo esportivo, pela posição que ocupa no espaço dos esportes. Mas, e no campo científico? O que vem sendo estudado sobre as mulheres futebolistas? O futebol feminino é um objeto de estudo recorrente nas dissertações e teses? Que espaço o futebol feminino ocupa na estrutura do campo acadêmico-científico?

Visando explanar de modo analítico tais questionamentos e atender ao objetivo do presente artigo, que é apresentar um mapeamento de teses e dissertações sobre o futebol feminino entre os anos de 1990 até 2010, orientamo-nos pela teoria dos campos, elaborada pelo sociólogo francês Pierre Bourdieu.

Considerando a influência entre diferentes campos, optamos por elaborar esse artigo abordando inicialmente aspectos sobre o campo esportivo e o campo acadêmicocientífico, evidenciando o esporte como objeto de estudo, e finalizaremos apresentando os dados coletados, que têm como finalidade ilustrar um cenário dos estudos sobre o futebol feminino no Brasil nos últimos 20 anos.

\footnotetext{
${ }^{2}$ Como forma de legalizar a permissibilidade das práticas esportivas, fazendo uso do poder público para interferir em tais ações, no ano de 1941 foi instituído o Decreto-Lei 3.199, que em seu artigo 54 estabelecia que: "às mulheres não se permitirá a prática de desportos incompatíveis com as condições de sua natureza, devendo, para este efeito, o Conselho Nacional de Desportos baixar as necessárias instruções às entidades desportivas do país". Esse decreto foi implementado em 1965 pelo Conselho Nacional de Desportes e proibia às mulheres "[...] a prática de lutas de qualquer natureza, futebol, futebol de salão, futebol de praia, polo aquático, polo, rugby, halterofilismo e baseball". A revogação veio a ocorrer no final dos anos 1970, contudo, algumas manifestações do futebol feminino continuavam a existir, mesmo diante das proibições, como demonstra estudo de Rigo et al. (2008) sobre o futebol feminino na década de 1950 na cidade de Pelotas RS. O inteiro teor do decreto está disponível em: $<$ http://www6.senado.gov.br/legislacao/ListaPublicacoes.actio n?id=152593>. Acesso em: 9 set. 2010. E a sua revogação, pela Lei 6.251/1975, está disponível em: $<$ http://www3.dataprev.gov.br/SISLEX/paginas/42/1975/6251.htm>. Acesso em: 9 set. 2010.

${ }^{3} \mathrm{O}$ habitus se configura como um sistema de disposições adquirido pela aprendizagem, que atua como um sistema de esquemas geradores, que originam estratégias que podem ser relacionadas aos interesses objetivos de seus autores sem terem sido criadas exatamente para este fim (BOURDIEU, 1983).
}

Pensar a Prática, Goiânia, v. 17, n. 4, out./dez. 2014 


\section{Métodos}

Visando ter um panorama nacional de produção de teses e dissertações que têm o futebol feminino como temática principal, mapeamos essas produções dos anos de 1990 até 2010, consultando o banco de dados da Coordenação de Aperfeiçoamento de Pessoal de Nível Superior (Capes), do Núcleo Brasileiro de Dissertações e Teses em Educação, Educação Física e Educação Especial (Nuteses) e 132 Currículos Lattes de pesquisadores sugeridos pelo site do Conselho Nacional de Desenvolvimento Científico e Tecnológico $(\mathrm{CNPq})$ que foram gerados pelo sistema ao pesquisarmos por assunto e por doutores, as seguintes palavras: "futebol feminino", "gênero", "esporte", "mulher". Foram consideradas somente as pesquisas concluídas. Essas informações serão apresentadas a seguir em um quadro constando: autor, orientador, título, instituição, programa de pós-graduação e ano.

Para complementar os dados e localizar os principais centros produtores de estudos sobre a temática, também realizamos um levantamento dos Grupos de Pesquisa existentes no Diretório de Grupos de Pesquisa do Conselho Nacional de Desenvolvimento Científico e Tecnológico (CNPq), por meio da busca pelas palavras-chave: "futebol" e "futebol feminino".

\section{Alguns elementos sobre a teoria dos campos}

Em termos analíticos, Bourdieu e Wacquant (2008) relatam que um campo pode ser definido como uma rede ou uma configuração de relações objetivas entre posições que são definidas objetivamente em sua existência e nas determinações que elas impõem aos seus ocupantes, por sua situação atual e potencial na estrutura da distribuição das diferentes espécies de poder cuja posse comanda o acesso aos lucros específicos que estão em jogo no campo.

De acordo com as leis gerais dos campos apresentada por Bourdieu (1983), campos tão diferentes como o da política e o da Filosofia apresentam leis de funcionamento invariantes, ou, no presente caso, o campo acadêmico e científico e o campo esportivo. A ambos os campos é comum a existência de objetos de disputa, como, por exemplo, o reconhecimento esportivo ou acadêmico, agentes propensos a travarem disputas em busca de tais objetos e estruturas que organizam o espaço social. Essas são algumas das leis gerais comuns aos espaços sociais. É isso que traduz a efetividade de uma teoria geral, pois torna-se possível a utilização do que se aprende sobre o funcionamento de cada campo particular para interrogar e interpretar outros campos.

Nesse âmbito, o autor destaca que, cada vez que um campo novo é estudado, são descobertas propriedades específicas de um campo particular, ao mesmo tempo que se avança no conhecimento dos mecanismos universais dos campos que se especificam em função de variáveis secundárias, como, por exemplo, variáveis nacionais.

Prosseguindo nessa esteira, um campo se define - entre outras coisas - por meio da demarcação dos objetos de disputas e dos interesses específicos que são irredutíveis aos objetos de disputas e dos interesses próprios de outros campos (BOURDIEU, 1983). O campo é um "[...] locus onde se trava uma luta concorrencial entre os atores em torno de interesses específicos que caracterizam a área em questão" (ORTIZ, 1983, p. 19).

Pensar a Prática, Goiânia, v. 17, n. 4, out./dez. 2014 
O interesse que estamos abordando diz respeito ao que se tem estudado sobre os esportes no campo acadêmico-científico, disputas "camufladas" entre agentes (dominantes e dominados) desse campo por objetos de pesquisa relevantes. Contudo, temos que advertir que objetos de pesquisa que são relevantes em outros espaços sociais, ou mesmo em outros campos, como o econômico, por exemplo, passam a ser, da mesma forma, obedecendo à mesma ordem hierárquica, relevantes ao espaço da produção científica.

Conduzindo o nosso olhar para o campo acadêmico-científico e o campo esportivo, identificamos que em ambos os espaços existem agentes detentores de capital específico, agentes legítimos que ocupam lugar de destaque na estrutura do campo, gerenciando e organizando as ações em uma "falsa" impressão de urgência destinada a determinadas modalidades ou aos objetos de pesquisa relevantes.

Lançando mão de nosso referencial teórico, podemos considerar que, no propósito da estrutura dos campos, aqueles que, num estado determinado de relação de força, monopolizam o capital específico tendem a estratégias de conservação (ortodoxia), ao passo que, os que possuem menos capital, normalmente os recém-chegados, tendem a estratégias de subversão (heresia) (BOURDIEU, 1983). Essa dinâmica de forças influencia, entre outras ações, a agenda de pesquisa e o posicionamento dos objetos de pesquisa na hierarquia do campo acadêmico-científico.

Seguindo nessa esteira de análise e reflexão bourdieusianas, apresentaremos algumas das principais noções acerca do campo esportivo e do campo acadêmico, como também, um quadro com informações sobre as teses e dissertações desenvolvidas sobre o futebol feminino, precedidas de análise.

\section{O campo esportivo}

Para iniciarmos a breve explanação sobre o campo esportivo, valemo-nos do entendimento de Marchi Júnior (2004) sobre a organização dos agentes e das disputas no interior dos campos. Para esse autor, há formas de disputas, lutas e competições, sendo que vislumbramos em cada uma delas a especificidade das relações entre o "novo" - que tenta garantir o direito de participação - e o dominante - que defende o monopólio objetivando excluir a concorrência. Vale frisarmos que é exatamente nessa linha de raciocínio que Bourdieu preconiza uma forma particular de entender o esporte moderno e, mais propriamente, abordando o espaço das práticas e manifestações esportivas e corporais.

O campo esportivo é compreendido por Bourdieu (1983) como um espaço dotado de relativa autonomia. Essa característica pode ser vislumbrada na história do futebol feminino com relação às influências exercidas, ou não, pelo campo político sobre as modalidades esportivas ou maneiras de praticá-las. Enquanto algumas ações do campo político atingiram diretamente a modalidade, outras pouco influenciaram. Como influência direta do campo político, citamos o decreto de 1941 que delimitava as práticas esportivas adequadas à natureza feminina, fato que teve/tem grande impacto na modalidade em questão - o futebol feminino. Do mesmo modo, ações políticas que visavam/visam maior participação das mulheres em outros espaços sociais que não os esportivos não influenciaram no campo esportivo, tanto que, por 40 anos, as jogadoras de futebol foram legalmente proibidas de exercer essa prática, mesmo com outros direitos concedidos às mulheres, tal qual o voto.

Pensar a Prática, Goiânia, v. 17, n. 4, out./dez. 2014 
Bourdieu (1983) ressalta que a constituição de um campo das práticas esportivas se acompanha da elaboração de uma filosofia política do esporte. Assim, a teoria do amadorismo faz do esporte uma prática tão desinteressada quanto a arte, embora o esporte seja mais conveniente do que a arte para a afirmação de virtudes viris dos futuros líderes. "O esporte é concebido como uma escola de coragem e virilidade, capaz de formar o caráter e inculcar a vontade de vencer [...], mas uma vontade de vencer que se conforma às regras" (BOURDIEU, 1983, p. 140).

Quando direcionamos o nosso olhar para o futebol praticado por mulheres no Brasil, temos uma estrutura semelhante àquela do futebol amador masculino, mas com menor oferta de campeonatos e de categorias para treino e jogo. Embora atualmente muitas atletas recebam para jogar, esse valor, em muitos casos, ainda é insuficiente para que elas possam se dedicar somente ao esporte, havendo a necessidade de outros empregos para complemento da renda. A organização de campeonatos, a estrutura física e financeira da grande maioria dos clubes de futebol feminino ainda é precária, fato que posiciona o futebol das mulheres às margens no subcampo do futebol no Brasil, ou nos termos bourdieusianos, o futebol de mulheres é dominado se comparado ao futebol dos homens.

Nesse cenário, é interessante relembrar que as frações dominantes da classe dominante tendem sempre a pensar sua oposição às frações dominadas por meio das oposições entre masculino e feminino, o viril e o afeminado, que passam a assumir diferentes conteúdos conforme suas épocas. Desse modo, Bourdieu (1983) demonstra que o esporte - em especial os esportes "viris", tal qual o futebol no Brasil -, assim como toda prática, é um objeto de lutas entre frações da classe dominante e também entre as classes sociais.

Outro "agravante" que posiciona o futebol feminino como dominado dentre essas disputas é a popularização da modalidade no sentido de consumo esportivo, pois, se pensarmos o início do século XX, o futebol era praticado e consumido por uma maioria massiva de homens. A possibilidade de profissionalização dos jogadores de futebol distanciou ainda mais a prática do público de mulheres, que nessa época caracterizavam-se ou como expectadoras dos jogos dos homens ou "jogavam bola" de forma recreativa. Com o passar dos anos as mulheres foram exibindo suas performances e deixando marcas importantes em participações internacionais, tais como Jogos Olímpios e Copa do Mundo de Futebol Feminino. No entanto, o consumo do futebol de mulheres ainda é pouco expressivo se comparado aos esportes mais populares junto ao público de mulheres, como o voleibol ou o tênis. Alicerçados em Bourdieu (1983 p. 142), temos como hipótese que a matriz e a vitrine de todas essas disputas se depositam no corpo e na forma de apresentação desse corpo, pois o campo esportivo é um espaço de "lutas pela definição do corpo legítimo e do uso legítimo do corpo".

Tomando como base o contexto brevemente apresentado, consideramos que o futebol masculino está tão arraigado à cultura brasileira que muitos estudiosos (dentre os quais citamos: Arlei Damo, 2002; e Luiz Henrique Toledo, 2000) consideram-no como parte da identidade nacional, ao passo que o futebol feminino, proibido por muitos anos, vem ocupando espaços à margem no subcampo do futebol.

Organizado e regido por uma maioria de homens, o futebol no Brasil dedica às mulheres um restrito espaço nas federações, assim como nos meios de comunicação, nos gramados e, principalmente, no incentivo e na aceitação da prática. Refletir sobre o uso do corpo no futebol feminino, impreterivelmente nos remete aos elementos eugênicos 
pregados no início do século XX, dentre os quais o de que para as mulheres não eram indicadas práticas esportivas em que seu corpo tivesse contato direto com o corpo da oponente, mais um indício que, somado aos anteriores, ajuda-nos a fomentar a hipótese de que o futebol feminino se posiciona na periferia, tanto do subcampo do futebol quanto do campo esportivo.

Como já mencionamos anteriormente, os campos não são espaços com fronteiras estritamente delimitadas. Embora tenham, cada um, sua lógica de funcionamento e relativa autonomia, eles se articulam entre si, já que cada campo tem seus dominantes e seus dominados, suas lutas pela conservação ou pela subversão, seus mecanismos de reprodução, etc. (BOURDIEU; WACQUANT, 2008).

Tanto as similitudes quanto as diferenças típicas do campo esportivo e do campo acadêmico poderão ser mais bem visualizadas a seguir, quando abordaremos as características predominantes do campo acadêmico.

\section{O campo acadêmico-científico}

Como já mencionamos anteriormente, existem leis gerais que regem campos diversos, permitindo a elaboração de uma teoria de qualquer espaço social, bem como as leis específicas que conferem ao campo uma relativa autonomia (BOURDIEU, 1983 e 2004). Sobre esse regime de leis, Bourdieu (2004, p. 20) ressalta: “[...] se, como o macrocosmo, ele é submetido a leis sociais, essas não são as mesmas. Se jamais escapa às imposições do macrocosmo, ele dispõe, em relação a este, uma autonomia parcial mais ou menos acentuada".

O que comanda os pontos de vista, as intervenções científicas, os lugares de publicação, os temas escolhidos e os objetos que suscitam interesse é influenciado pela estrutura de relações objetivas entre os diversos agentes do campo. A agenda de interesses de periódicos científicos, a visibilidade e relevância atribuída a um objeto de estudo são exemplos dessas determinações. A posição que o agente ocupa no campo também interfere nesse processo de tomada de decisão, sendo esse fator um critério importante para a leitura do campo científico (BOURDIEU, 1983). Sendo assim, a escolha por um objeto de pesquisa não é isenta dessas influências, que acabam por marcar de forma positiva ou negativa esse objeto.

Além das interferências externas, o campo científico possui seus conflitos internos. É um espaço onde lutas são travadas para conservá-lo ou modificá-lo, e as relações de força e dominação são constantes. Os agentes criam o espaço e esse só existe por intermédio dos agentes que ali se encontram e mantêm relações objetivas entre si. A estrutura dessas relações é que define as ações tomadas no campo, como a escolha de objetos de pesquisa, os lugares de publicação, entre outras questões. Nesse sentido, é em decorrência da posição que o agente ocupa nessa estrutura que lhe são permitidas ou vetadas certas ações, orientando assim sua tomada de decisão (BOURDIEU, 2004).

Dessa forma, é necessário perceber que tipo de relações os pesquisadores do futebol feminino estabelecem com seus pares e entre si, como, por exemplo, a inserção de grupos de pesquisa, para verificar indícios de que lugar no campo eles ocupam.

Sobretudo, identificam-se também influências políticas de grupos de autores em posição dominante no campo acadêmico-científico, de modo que a inserção de novas 
ideias e autores é dificultada, no sentido de que a hierarquia nesse espaço seja mantida. Em se tratando do objeto de estudo, um mesmo agente pode ocupar posição dominada e dominante. Por exemplo: no campo dos estudos sobre o futebol, agentes que estudam o futebol feminino aparecem como dominados ao pensarmos a quantidade de estudos direcionados para o futebol (dos homens), contudo, no grupo dos agentes que estudam o futebol feminino, existem os dominantes que, de certa forma, organizam e promovem o agendamento dos temas a serem abordados principalmente pelos agentes dominados, que buscam a entrada e o estabelecimento nesse cenário.

Bourdieu (2004) destaca que os agentes fazem os fatos científicos e até mesmo o campo científico. No entanto, ocupam uma posição nesse espaço social, contribuindo para a definição das possibilidades e impossibilidades desse campo. Essa estrutura do campo científico é determinada pela distribuição do capital próprio desse espaço social em um momento. Os agentes distribuídos pelo seu volume de capital determinam a estrutura em proporção ao seu peso e o peso dos demais. A estrutura realiza sua pressão em cada agente, de modo diferenciado, de acordo com o seu capital (BOURDIEU, 2004).

Pesquisadores do futebol feminino, nesse cenário e nesse momento, parecem estar à margem do campo, não tendo ações expressivas, inserções institucionais ou grupos de pesquisa formal. Devido ao pouco capital específico que possuem no momento, fica definida uma série de impossibilidades para esses estudiosos no campo acadêmico e científico. Essas impossibilidades podem ser alteradas conforme se realizam ações no campo e se procuram posições mais prestigiosas mediante o acúmulo de capital específico.

Assim, os agentes não são passivos, engajam-se na disputa de determinados objetos, não sendo somente levados pelas forças do campo. O habitus pode levá-los a se opor a essas forças. Os que não possuem o habitus do campo no qual estão inseridos correm o constante risco de estar defasados, deslocados, sem entender as regras do jogo que ocorre ao seu redor. Mas eles também têm a possibilidade de se opor a esse jogo, não se submeter às forças do campo e tentar modificar as estruturas que os pressionam, para conformálas de acordo com as suas disposições (BOURDIEU, 2004).

Podemos cogitar que existe uma semelhança entre o espaço social e o espaço das práticas esportivas, na qual as posições ocupadas no campo esportivo são similares a posições do campo acadêmico e científico. Sendo assim, entendemos que a posição ocupada pelo Futebol Feminino no campo esportivo e o interesse científico que ele suscita acabam por refletir na produção acadêmica sobre a temática.

\section{Resultados e discussão}

\section{Um cenário do futebol feminino no campo acadêmico-científico}

Subsidiados pelos conceitos teóricos apresentados até então, e com o objetivo de construir um cenário do futebol feminino no campo acadêmico-científico mapeamos as produções (teses e dissertações) e os grupos de pesquisas que abordam essa temática. Após investigação nos grupos de pesquisa, foram identificados 25 grupos que abordam a temática futebol como objeto central ou em uma de suas linhas de pesquisa. Dentre todos esses grupos, notamos que o tema futebol feminino sequer apareceu, ou, então, não foi especificado em nenhum desses grupos.

Pensar a Prática, Goiânia, v. 17, n. 4, out./dez. 2014 
A ausência de grupos de pesquisa ou de linhas de pesquisas que direcionem suas análises para o futebol feminino ilustra, dentre outros fatores, a escassez de pesquisadores ativos com foco nessa temática, bem como a pouca importância que é destinada ao esporte feminino como objeto de estudo relevante. Se considerarmos a semelhança entre os campos esportivo e acadêmico-científico, podemos atribuir esse fato às raízes históricas dessa modalidade.

Corroborando essas afirmações, trazemos as informações relacionadas à produção de dissertações e teses entre os anos de 1990 e 2010, onde foram encontradas oito dissertações. Dessas, a primeira dissertação defendida data do ano de 1997; outras três no ano de 2003; e, nos anos de 2001, 2005, 2009 e 2010, foram defendidas uma em cada um desses anos. Nesse mesmo mapeamento, identificamos três teses, duas defendidas no ano de 2010 e uma em 2006.

Embora não existam linhas de pesquisa direcionadas especificamente ao futebol feminino, por meio dos quadros a seguir, podemos reconhecer alguns agentes que assumem posição de destaque - com relação ao objeto de estudo futebol feminino - no campo acadêmico-científico em decorrência dos estudos realizados, orientados e de participação em bancas de defesa de trabalhos de pós-graduação (mestrado e doutorado). Nesses quadros, apresentamos o ano de publicação, o título dos trabalhos, os autores, os orientadores e a formação das bancas de defesa ${ }^{4}$, bem como as instituições de ensino onde foram elaborados os estudos, separados por dissertações e teses.

\begin{tabular}{|c|c|c|c|}
\hline \multicolumn{4}{|c|}{ Dissertações } \\
\hline Ano & $\begin{array}{c}\text { Título } \\
\end{array}$ & Autor(a) & Orientador(a) \\
\hline 1997 & $\begin{array}{l}\text { Representações da mulher que } \\
\text { joga futebol }\end{array}$ & $\begin{array}{l}\text { Lúcia da Costa Leite } \\
\text { Reis }\end{array}$ & $\begin{array}{l}\text { Sebastião Josué } \\
\text { Votre }\end{array}$ \\
\hline \multicolumn{4}{|c|}{ Instituição: Universidade Gama Filho - Mestrado em Educação Física } \\
\hline 2001 & $\begin{array}{l}\text { A construção da imagem social } \\
\text { da atleta de futebol feminino }\end{array}$ & $\begin{array}{l}\text { Rosângela de Sena } \\
\text { Almeida }\end{array}$ & $\begin{array}{l}\text { Roberto Ferreira } \\
\text { dos Santos }\end{array}$ \\
\hline \multicolumn{4}{|c|}{ Banca: Paulo de Tarso Veras Farinatti / Antonio Jorge Goncalves Soares } \\
\hline \multicolumn{4}{|c|}{$\begin{array}{l}\text { Instituição: Universidade do Estado do Rio de Janeiro - Mestrado em Ciências do Des- } \\
\text { porto }\end{array}$} \\
\hline 2003 & $\begin{array}{l}\text { Futebol feminino: análise dos dis- } \\
\text { cursos dos sujeitos envolvidos em } \\
\text { uma competição infantil entre es- } \\
\text { colas públicas em João Pessoa } \\
\text { (PB) }\end{array}$ & Lígia Luiz de Freitas & $\begin{array}{c}\text { Maria Eulina } \\
\text { Pessoa de Carva- } \\
\text { lho }\end{array}$ \\
\hline \multicolumn{4}{|c|}{$\begin{array}{c}\text { Banca: Terezinha Petrúcia da Nóbrega / Maria Zuleide da Costa Pereira / Iraquitan de } \\
\text { Oliveira Caminha }\end{array}$} \\
\hline \multicolumn{4}{|c|}{ Instituição: Universidade Federal da Paraíba - Mestrado em Educação } \\
\hline 2003 & Corpo mulher no esporte: a ques- & Wilington Antônio & Wagner Wey \\
\hline
\end{tabular}

${ }^{4}$ As formações das bancas de defesas das dissertações dos anos de 1997 e 2010 não foram encontradas.

Pensar a Prática, Goiânia, v. 17, n. 4, out./dez. 2014 


\begin{tabular}{|c|c|c|c|}
\hline & tão da prática do futebol & Giarola & Moreira \\
\hline \multicolumn{3}{|c|}{ Banca: Tânia Mara Vieira Sampaio / José Antonio S. Barbosa } \\
\hline Instituição: Universidade Metodista de Piracicaba - Mestrado em Educação Física
\end{tabular}




\begin{tabular}{|c|c|c|c|}
\hline \multicolumn{4}{|c|}{ Teses } \\
\hline Ano & Título & Autor(a) & Orientador(a) \\
\hline 2006 & $\begin{array}{l}\text { Femininos e masculinos no futebol bra- } \\
\text { sileiro }\end{array}$ & $\begin{array}{l}\text { Jorge Dorffman } \\
\text { Knijnik }\end{array}$ & $\begin{array}{l}\text { Esdras Vascon- } \\
\text { cellos }\end{array}$ \\
\hline \multicolumn{4}{|c|}{$\begin{array}{c}\text { Banca: Dante de Rose Junior / Afonso Antônio Machado / Yvette Piha Lehman / Cláudia } \\
\text { Pereira Vianna }\end{array}$} \\
\hline \multicolumn{4}{|c|}{$\begin{array}{c}\text { Instituição: Instituto de Psicologia da Universidade de São Paulo - Doutorado em Psi- } \\
\text { cologia Social }\end{array}$} \\
\hline 2010 & $\begin{array}{l}\text { Meninas que jogam bola: identidades e } \\
\text { projetos das praticantes de esportes co- } \\
\text { letivos de confronto no lazer }\end{array}$ & $\begin{array}{l}\text { Alexandre Jackson } \\
\text { Chan Vianna }\end{array}$ & $\begin{array}{l}\text { Ludmila } \\
\text { Mourão }\end{array}$ \\
\hline \multicolumn{4}{|c|}{$\begin{array}{c}\text { Banca: Antonio Jorge Gonçalves Soares / Victor Andrade Melo / Hugo R. Lovisolo / } \\
\text { Gilberto Velho }\end{array}$} \\
\hline \multicolumn{4}{|c|}{ Instituição: Universidade Gama Filho - Doutorado em Educação Física } \\
\hline 2010 & $\begin{array}{l}\text { Futebol é coisa de mulher! Um estudo } \\
\text { etnográfico sobre o lugar feminino no } \\
\text { futebol clubístico }\end{array}$ & $\begin{array}{l}\text { Marcelo Pizarro } \\
\text { Noronha }\end{array}$ & $\begin{array}{l}\text { Edison Luis } \\
\text { Gastaldo }\end{array}$ \\
\hline \multicolumn{4}{|c|}{ Banca: Simoni Lahud Guedes / Silvana Goellner / Carlos Gadea / José Rogério Lopes } \\
\hline \multicolumn{4}{|c|}{ Instituição: Universidade do Vale do Rio dos Sinos - Doutorado em Ciências Sociais } \\
\hline
\end{tabular}

Considerando que o esporte é um objeto de estudo que vem ocupando espaço nas mais variadas áreas, os cientistas do esporte podem ser considerados em algumas áreas como "recém-chegados", ou, ainda, como agentes que estão lutando para ocupar espaço dentro do campo acadêmico-científico utilizando-se de estratégias comuns a esse meio, tais como publicações em periódicos de impacto e orientações de trabalhos de pósgraduação. Contudo, essas estratégias não garantem a legitimidade em curto espaço de tempo, é necessário que sejam incorporados ao habitus do pesquisador elementos constituidores desse campo, para que esses novos agentes sejam também dotados de capital científico, reconhecimento, prestígio, entre outras propriedades, pelos pares, para então ocuparem lugar privilegiado nesse contexto.

Em se tratando de "recém-chegados", podemos localizar o futebol feminino como um esporte recente, se considerarmos a organização administrativa e técnica das equipes, a existência de campeonatos regulares e, também, a possibilidade de ter no futebol uma profissão, fatos que ficaram mais evidentes após 1979, com a revogação do decreto anteriormente comentado. A legitimidade feminina para a prática do futebol perpassa outros elementos e estratégias referentes à performance e à representação dos corpos, características que, embora em um primeiro momento possam parecer alheias ao campo científico, influenciam a difusão da temática no espaço acadêmico.

Somadas a essas breves discussões acerca do futebol feminino no campo esportivo e no campo científico aos dados coletados, levantaremos algumas hipóteses a fim de compreender a posição que essa modalidade esportiva ocupa no campo científico. Inicial- 
mente remetemo-nos à noção de distinção (BOURDIEU, 2009). Algumas temáticas, tais quais a economia ou a política, assumem posições de destaque no rol de objetos de estudo relevantes, enquanto o esporte, por caracterizar uma prática menos distinta em relação aos meios de produção, assume outro lugar (de menor destaque) no espaço dos objetos de estudo relevantes.

Ainda em se tratando de objetos de estudo relevantes, observamos que dentro do rol dos esportes, o futebol assume grande destaque, como observamos anteriormente na explanação sobre os grupos e linhas de pesquisa; já o futebol feminino nem foi mencionado. $\mathrm{O}$ futebol no Brasil ainda assume um caráter masculino, fato que pode subsidiar mais uma de nossas hipóteses da restrição de trabalhos acadêmicos e científicos tendo o futebol feminino como foco.

Nesse contexto, revisitamos a estrutura dos campos e os enfrentamentos entre os agentes dominantes e dominados em cada um dos campos. Os dominantes são legítimos na produção de conhecimento, possuem os capitais específicos para permanecer nessa estrutura, são esses agentes que determinam - entre outras coisas - os objetos de estudos relevantes e a legitimidade dos pesquisadores.

Os resultados encontrados demonstram que o futebol feminino parece assumir uma posição à margem, tanto com relação ao campo esportivo quanto ao campo acadêmico-científico. Embora por motivos peculiares de cada campo, o objeto de estudo em questão parece localizar-se em posição muito similar nos dois diferentes espaços, fato este que reforça a semelhança dos campos percebida.

A busca pela legitimidade do futebol feminino como uma prática esportiva também encontra no campo acadêmico-científico um espaço que está no processo de lutas que visam legitimar essa modalidade esportiva como objeto de estudo relevante. Nessa esteira de análise chamamos a atenção para a diversidade dos programas de pós-graduação que desenvolveram os trabalhos tanto em nível de mestrado quanto de doutorado, e que embora a maioria seja de educação física - ou que apresentem nomenclaturas próximas, como movimento humano - outros programas como de ciências sociais, psicologia social e memória social também tiveram o futebol feminino como temática de estudo.

Mesmo com a escassez de teses e dissertações acerca dessa temática, somado ao fato de não termos encontrado nenhum grupo ou linha de pesquisa que aborde o futebol feminino, a diversidade de instituições onde esses estudos se originaram é um dado interessante, tendo em vista que somente três trabalhos, duas dissertações e uma tese foram desenvolvidos em uma única instituição, a Universidade Gama Filho.

Com base nas informações descritas até o presente momento, consideramos que o objeto de estudo "futebol feminino", mesmo estando localizado às margens do campo acadêmico-científico, é desenvolvido em diferentes polos de produção científica e acadêmica. No entanto, quando se trata do campo esportivo, a prática com caracteres que se aproximam da profissionalização é identificada com maior veemência em focos específicos, tal qual no estado de São Paulo. Nesse tocante, concluímos que a prática da modalidade está em processo lento de inserção e que muito possivelmente, quando o futebol feminino brasileiro atingir maior nível de divulgação, seja no campo midiático ou no campo esportivo, esse reflexo influenciará no campo científico, por meio da escolha de tal prática como objeto de estudos.

Pensar a Prática, Goiânia, v. 17, n. 4, out./dez. 2014 
WOMEN SOCCER IN THE BRAZILIAN ACADEMIC FIELD: A MAPPING OF THESIS AND DISSERTATIONS (1990-2010)

\begin{abstract}
The aim of this article is to present a mapping of the thesis and dissertations about women soccer from 1990 to 2010. For this purpose we researched in the Capes database, at Nuteses and 132 researchers curricula at the CNPq database. The search contemplated the curricula of the doctoral degree researchers and the keywords: women soccer, gender, sport and woman. We considered only the complete surveys, of which three were thesis and nine were dissertations. As results, we perceived a possible homology between the sportive and academic field, since the social space the women soccer occupied in the sportive field is similar to the space this modality occupies in the academic field: a peripheral space.

Keywords: Women soccer. Brazil. Scientific production. Fields theory.

\section{EL FÚTBOL FEMENINO EN EL CAMPO ACADÉMICO BRASILEÑO: MAPEO DE TESIS Y DISERTACIONES (1990-2010)}

\section{Resumen}

El objetivo de este trabajo es presentar un mapeo de las tesis y disertaciones a cerca del fútbol femenino entre los años de 1990 y 2010. Para tanto, consultamos la base de dados de la Capes, del Nuteses y 132 Currículos Lattes de pesquisadores designados por el sitio web del CNPq en una consulta por tema y por doctores, con las palabras clave: fútbol femenino, género, deporte y mujer. Se consideraron sólo las pesquisas ya realizadas, de las cuales, tres son tesis y nueve son disertaciones. Como resultados, encontramos una posible homología entre los campos deportivo y académico, ya que tanto el espacio social ocupado por el fútbol femenino en el campo de deportes como el objeto de estudio en el campo académico son considerados periféricos.
\end{abstract}

Palavras clave: Fútbol femenino. Brasil. Producción científica. Teoria de los campos.

\title{
Referências
}

BOURDIEU, P. Questões de sociologia. Rio de Janeiro: Marco Zero, 1983.

BOURDIEU, P. Coisas ditas. São Paulo: Brasiliense, 1990.

BOURDIEU, P. Os usos sociais da ciência: por uma sociologia clínica do campo científico. São Paulo: Unesp, 2004.

BOURDIEU, P. O senso prático. Petrópolis: Vozes, 2009.

BOURDIEU, P.; WACQUANT, L. Una invitación a la sociología reflexiva. Buenos Aires: Siglo XXI, 2008.

DAMO, A, S. Futebol e identidade social: uma leitura antropológica das rivalidades entre torcedores e clubes. Porto Alegre: Editora da UFRGS, 2002. 
FRANZINI, F. Futebol é "coisa para macho"? Pequeno esboço para uma história das mulheres no país do futebol. Revista Brasileira de História, São Paulo, v. 25, n. 50, p. 315358, dez. 2005. Disponível em: <http://www.scielo.br/pdf/rbh/v25n50/28282.pdf>. Acesso em: 4 jun. 2014.

GOELLNER, S. V. O esporte e a espetacularização dos corpos femininos. Labrys: Estudos Feministas, n. 4, ago./dez. 2003. Disponível em: <www.tanianavarroswain.com.br/labrys/labrys4/textos/silvana1.htm>. Acesso em: 12 jan. 2015.

GOELLNER, S. V. Mulher e esporte no Brasil: entre incentivos e interdições elas fazem história. Revista Pensar a Prática, v. 8, n. 1, p. 85-100, jan./jun. 2005a.

GOELLNER, S. V. Mulheres e futebol no Brasil: entre sombras e visibilidades. Revista Brasileira de Educação Física e Esporte, São Paulo, v. 19, n. 2, p. 143-151, abr./jun. 2005b.

JAEGER, A. Mulheres atletas da potencialização muscular e a construção de arquiteturas corporais no fisiculturismo. $237 \mathrm{f}$. Tese (Doutorado) - Escola de Educação Física da Universidade Federal do Rio Grande do Sul, Porto Alegre, 2009.

MARCHI JÚNIOR, W. “Sacando” o voleibol. São Paulo: Hucitec, 2004.

MOURÃO, L. Representação social da mulher brasileira nas atividades físico-desportivas: da segregação à democratização. Movimento, Porto Alegre, n. 13, p. 5-18, jul./dez. 2000 .

MOURÃO, L.; MOREL, M. As narrativas sobre o futebol feminino: o discurso da mídia impressa em campo. Revista Brasileira de Ciências do Esporte, Florianópolis, v. 26, n. 2 , ago. 2008. Disponível em: <http://cbce.tempsite.ws/revista/index.php/RBCE/article/view/148/157>. Acesso em: 4 jun. 2014.

ORTIZ, R. A procura de uma sociologia da prática. In: ORTIZ, R. (Org.). Pierre Bourdieu: sociologia. São Paulo: Ática, 1983. p. 7-29.

RIGO, L. C. et al. Notas acerca do futebol feminino pelotense em 1950: um estudo genealógico. Revista Brasileira de Ciências do Esporte, Campinas, v. 29, n. 3, p. 173188, maio 2008.

SALVINI, L. Novo Mundo Futebol Clube e o "velho mundo" do futebol: considerações sociológicas sobre o habitus esportivo de jogadoras de futebol. $178 \mathrm{f}$. Dissertação (Mestrado em Educação Física) - Curso de Educação Física, Departamento de Educação Física, Universidade Federal do Paraná, Curitiba, 2012. 
TOLEDO, L, H. No país do futebol. Rio de Janeiro: Jorge Zahar Ed., 2000.

Recebido em: 25/08/2014

Revisado em: 16/10/2014

Aprovado em: 14/11/2014

Endereço para correspondência:

leila.salvini@gmail.com

Leila Salvini

Universidade Federal do Paraná

Rua XV de Novembro, 1299

CEP 80.060-000 | Centro | Curitiba | PR | Brasil

Pensar a Prática, Goiânia, v. 17, n. 4, out./dez. 2014 